\title{
Lenvatinib in Advanced Hepatocellular Carcinoma
}

\author{
Masatoshi Kudo \\ Department of Gastroenterology and Hepatology, Kindai University Faculty of Medicine, \\ Osaka-Sayama, Japan
}

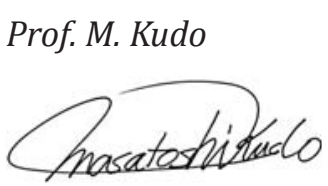

Editor Liver Cancer

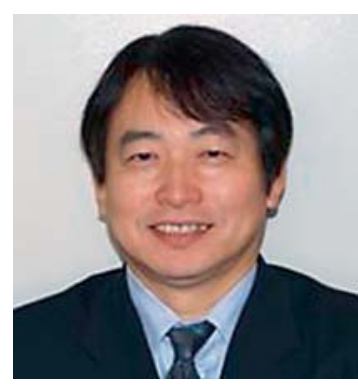

\section{Introduction}

Sorafenib has been the standard therapy for patients with unresectable hepatocellular carcinoma (HCC) since 2007, when it was shown to prolong survival, as verified in the SHARP trial [1] and a study conducted in the Asia-Pacific region [2].

Since then, other molecular-targeted agents superior to sorafenib in efficacy or safety in the first-line treatment of HCC were developed and tested in clinical trials (Table 1) [3]. However, a superiority trial of sunitinib [4] and noninferiority followed by superiority studies of brivanib or linifanib versus sorafenib $[5,6]$ were reported as negative; a superiority trial of sorafenib plus erlotinib versus sorafenib was also unsuccessful [7]. Furthermore, both the SARAH (sorafenib versus radioembolization in advanced HCC) and the SIRveNIB (study to compare selective internal radiation therapy versus sorafenib in locally advanced HCC) trials failed, as reported at the 2017 annual meetings of the European Association for the Study of the Liver and the American Society of Clinical Oncology (ASCO) $[8,9]$. These negative trials indirectly indicate the difficulty in achieving the predefined primary overall survival (OS) endpoint in HCC patients and the better-than-expected superiority of sorafenib in prolonging survival.

Against this background, the success of the phase III noninferiority trial of lenvatinib versus sorafenib with OS as the endpoint, as presented at the 2017 ASCO annual meeting, is an unprecedented and groundbreaking achievement in the past 10 years, promising an alternative molecular-targeted therapy option for HCC patients [10]. 
Kudo: Lenvatinib in Advanced Hepatocellular Carcinoma

Table 1. Phase III clinical trials of the agents targeting for hepatocellular carcinoma

\begin{tabular}{|c|c|c|c|}
\hline $\begin{array}{l}\text { Early stage } \\
\text { (adjuvant) }\end{array}$ & $\begin{array}{l}\text { Peretinoin vs. placebo (NIK-333) } \\
\text { Sorafenib vs. placebo (STORM) } \\
\text { Peretinoin vs. placebo (NIK-333) }\end{array}$ & $\begin{array}{l}\text { Phase II/III } \\
\text { Phase III } \\
\text { Phase III }\end{array}$ & $\begin{array}{l}\text { Negative } \\
\text { Negative } \\
\text { Ongoing }\end{array}$ \\
\hline $\begin{array}{l}\text { Intermediate stage } \\
\text { (combination with } \\
\text { TACE) }\end{array}$ & $\begin{array}{l}\text { Sorafenib (Post TACE) } \\
\text { Brivanib (BRISK-TA) } \\
\text { TSU-68 (ORIENTAL) } \\
\text { Sorafenib (TACE 2) }\end{array}$ & $\begin{array}{l}\text { Phase III } \\
\text { Phase III } \\
\text { Phase III } \\
\text { Phase III }\end{array}$ & $\begin{array}{l}\text { Negative } \\
\text { Terminated } \\
\text { Terminated } \\
\text { Negative }\end{array}$ \\
\hline $\begin{array}{l}\text { Advanced stage } \\
\text { (first line) }\end{array}$ & $\begin{array}{l}\text { Sunitinib vs. sorafenib (SUN1170) } \\
\text { Linifanib vs. sorafenib (LiGHT) } \\
\text { Brivanib vs. sorafenib (BRISK-FL) } \\
\text { SOR + erlotinib vs. sorafenib (SEARCH) } \\
\text { SOR + doxorubicin vs. sorafenib (CALGB808028) } \\
\text { Sorafenib + HAIC (SILIUS) } \\
\text { Lenvatinib vs. sorafenib (REFLECT) } \\
\text { Nivolumab vs. sorafenib (CheckMate-459) } \\
\text { SIRT vs. sorafenib (SARAH) } \\
\text { SIRT vs. sorafenib (SIRveNIB) }\end{array}$ & $\begin{array}{l}\text { Phase III } \\
\text { Phase III } \\
\text { Phase III } \\
\text { Phase III } \\
\text { Phase III } \\
\text { Phase III } \\
\text { Phase III } \\
\text { Phase III } \\
\text { Phase III } \\
\text { Phase III }\end{array}$ & $\begin{array}{l}\text { Negative } \\
\text { Negative } \\
\text { Negative } \\
\text { Negative } \\
\text { Negative } \\
\text { Negative } \\
\text { Positive } \\
\text { Ongoing } \\
\text { Negative } \\
\text { Negative }\end{array}$ \\
\hline $\begin{array}{l}\text { Advanced stage } \\
\text { (second line) }\end{array}$ & $\begin{array}{l}\text { Brivanib vs. placebo (BRISK-PS) } \\
\text { Everolimus vs. placebo (EVOLVE-1) } \\
\text { Ramcirumab vs. Placebo (REACH) } \\
\text { S-1 vs. placebo (S-CUBE) } \\
\text { Tivantinib vs. placebo (METIV-HCC) } \\
\text { Regorafenib vs. placebo (RESOUCE) } \\
\text { Ramcirumab vs. placebo (REACH-2) }\end{array}$ & $\begin{array}{l}\text { Phase III } \\
\text { Phase III } \\
\text { Phase III } \\
\text { Phase III } \\
\text { Phase III } \\
\text { Phase III } \\
\text { Phase III }\end{array}$ & $\begin{array}{l}\text { Negative } \\
\text { Negative } \\
\text { Negative } \\
\text { Negative } \\
\text { Negative } \\
\text { Positive } \\
\text { Ongoing }\end{array}$ \\
\hline
\end{tabular}

HAIC, hepatic arterial infusion chemotherapy.

\section{History of the Development of Lenvatinib}

Lenvatinib, which was discovered in an exploratory study for an angiogenesis inhibitor, mainly inhibits vascular endothelial growth factor (VEGF) receptors (VEGFR1, VEGFR2, and VEGFR3), fibroblast growth factor (FGF) receptors (FGFR1, FGFR2, FGFR3, and FGFR4), KIT, and RET [11]. Lenvatinib is an extremely effective inhibitor of tumor angiogenesis that simultaneously interferes with these tumor angiogenesis-related molecules and suppresses growth signals mediated by VEGFRs and FGFRs [12].

A daily dose of $24 \mathrm{mg}$ was initially determined based on the results of a phase I trial for the treatment of solid tumors and other subsequent studies in other types of cancer; however, the dose was reduced to $12 \mathrm{mg}$ after another phase I trial addressing the effect of lenvatinib metabolism on liver function in HCC patients [13].

The phase II study, conducted in Japan and South Korea, confirmed the high antitumor activity of lenvatinib with manageable adverse events in HCC patients [14].

\section{Relationship between Safety and Body Weight in the HCC Phase II Trial}

In the phase II study, a uniform daily dose of $12 \mathrm{mg}$ irrespective of body weight and surface area led to dose reduction in a large proportion of patients: dose adjustment in 34 of 46 patients $(74 \%)$ because of treatment-related adverse events and withdrawal in 10 patients (22\%) because of toxicity. Close examination of patient characteristics indicated that body weight and serum lenvatinib levels were likely to be associated with dose reduction or early 


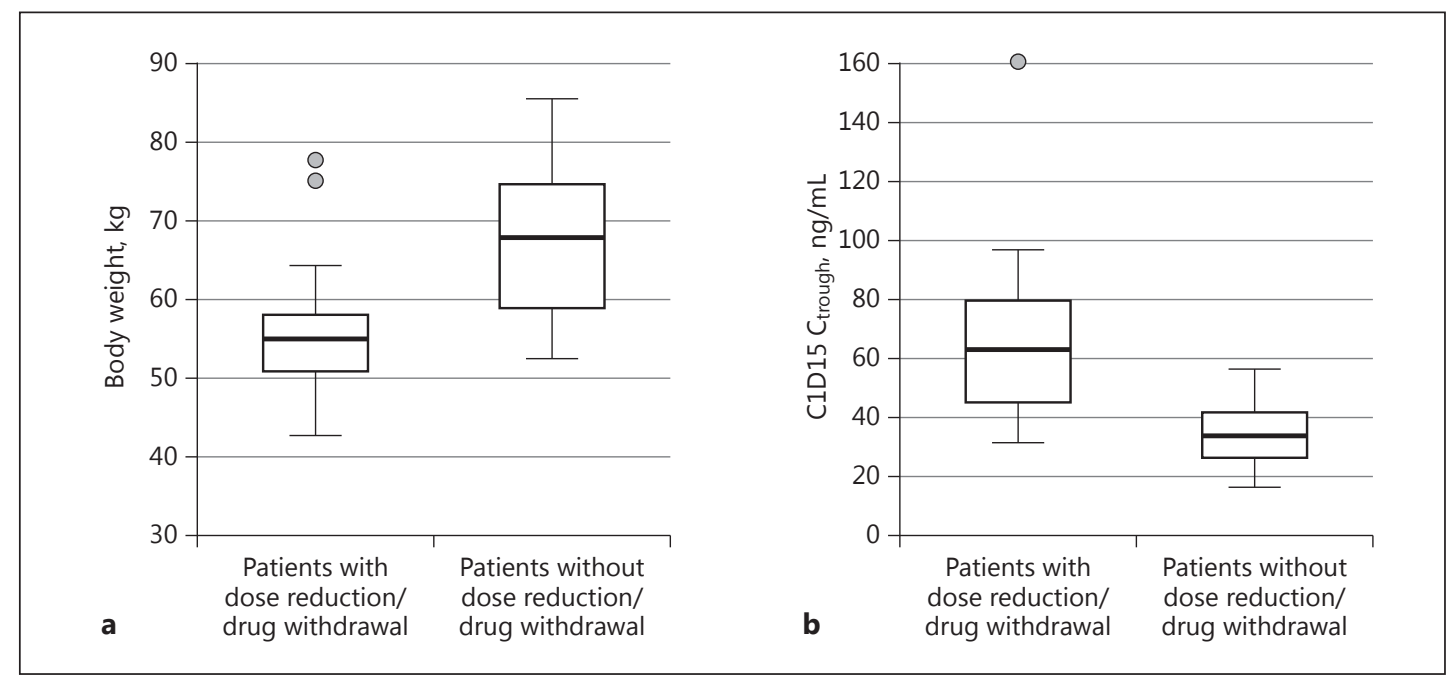

Fig. 1. a Boxplot of body weight for patients with and without adverse events that led to dose reduction or dose withdrawal within 30 days of lenvatinib treatment initiation. $\mathbf{b}$ Boxplot of lenvatinib $\mathrm{C}_{\text {trough }}$ level 15 days after lenvatinib treatment initiation for patients with and without adverse events that led to dose reduction or withdrawal within 30 days. C1D15, cycle 1 day 15; $C_{\text {trough }}$ minimum concentration of lenvatinib. Cited from Ikeda et al. [14].

withdrawal. More precisely, patients who had dose reduction or early therapy withdrawal within 30 days of lenvatinib treatment were significantly lighter (median weight, 54.1 vs. 67.6 $\mathrm{kg}$ ) and had a significantly higher minimum plasma concentration of lenvatinib (trough concentration [C1D15C trough], 62.4 vs. 33.9 ng/mL; Fig. 1).

\section{Pharmacokinetics of Lenvatinib and Rationale for Weight-Based Dosing in HCC Patients}

\section{Relationship between Body Weight and Plasma Level of Lenvatinib in HCC Patients}

Following the phase I and II studies, population pharmacokinetics was analyzed in 65 HCC patients enrolled in these trials and in 155 patients with solid cancer and 232 healthy individuals enrolled in other clinical studies [15]. A relationship between body weight and plasma lenvatinib level (represented by the area under the blood concentration-time curve [AUC]) was detected, indicating that exposure to lenvatinib increased as body weight decreased (Fig. 2). This trend was more prominent in HCC patients than in patients with other types of solid cancer, suggesting that this relationship particularly impacts HCC patients.

\section{Relationship between the Pharmacokinetics of Lenvatinib and Dose Reduction or Withdrawal in HCC Patients}

Forty-five patients enrolled in trials for HCC treatment were grouped into a low AUC group $(<2,050 \mathrm{ng} \times \mathrm{h} / \mathrm{mL})$, intermediate AUC group ( $>2,050 \mathrm{ng} \times \mathrm{h} / \mathrm{mL}, \leq 2,750 \mathrm{ng} \times \mathrm{h} / \mathrm{mL})$, and high AUC group ( $>2,750 \mathrm{ng} \times \mathrm{h} / \mathrm{mL})$ to examine the relationship between AUC and time to dose reduction or withdrawal of lenvatinib. Kaplan-Meier plots clearly showed that time to dose reduction or withdrawal decreased as AUC increased (Fig. 3a). Body weight was also related to time to dose reduction or withdrawal; time to dose reduction or withdrawal decreased as body weight decreased, demonstrating that dose reduction or withdrawal is required earlier in lighter patients than in heavier patients (Fig. 3b). 


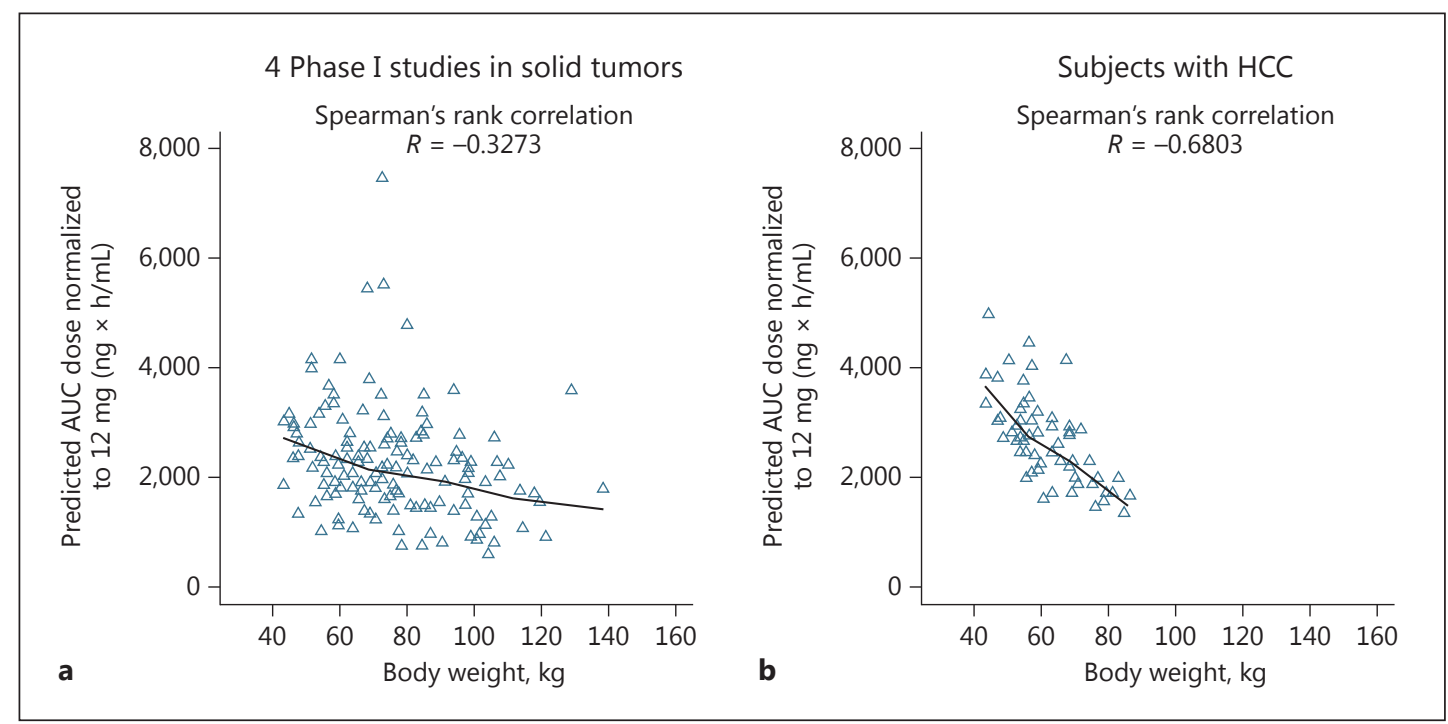

Fig. 2. Relationship between model-predicted lenvatinib exposure and body weight. AUC, area under the plasma concentration-time curve at steady state; HCC, hepatocellular carcinoma. Cited from Tamai et al. [15].

Fig. 3. Kaplan-Meier plots of time to first TEAE leading to lenvatinib withdrawal or dose reduction stratified by tertiles of lenvatinib AUC (a) or body weight (b). AUC, area under the plasma concentration-time curve at steady state; TEAE, treatment-emergent adverse event; BW, body weight. Cited from Tamai et al. [15]. 


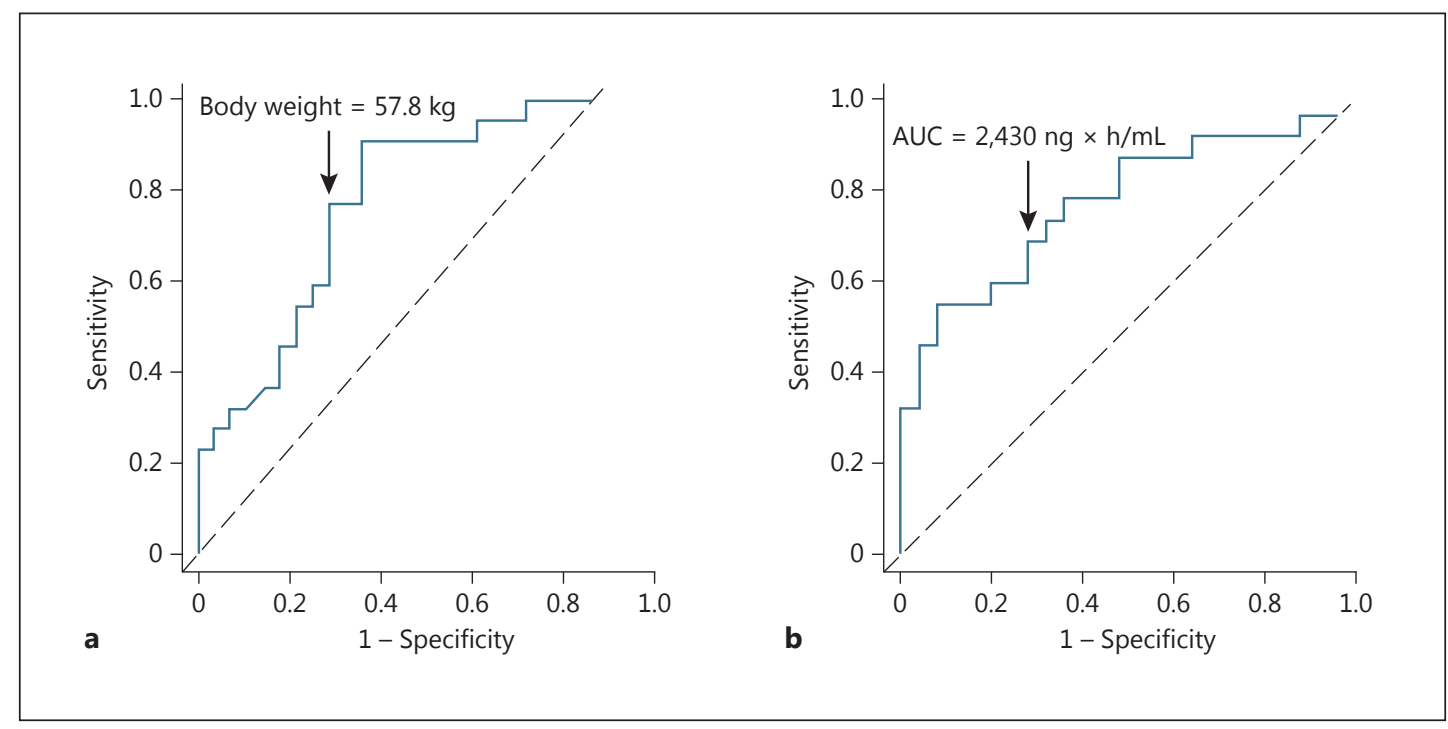

Fig. 4. ROC curve for the occurrence of TEAEs leading to dose reduction or discontinuation during cycle 1. a Body weight. b Lenvatinib AUC. AUC, area under plasma concentration-time curve at steady state; ROC, receiver operating characteristics; TEAE, treatment-emergent adverse event. Cited from Tamai et al. [15].

Optimal Body Weight and AUC Cutoff Value for Lenvatinib Adjustment in HCC Treatment

Strong correlations between lenvatinib withdrawal, blood concentration (AUC), and body weight indicated that dose adjustment by body weight and AUC may improve the safety of lenvatinib in the treatment of patients with HCC. Sensitivity and specificity values for predicting early occurrence (within 30 days after the start of therapy) of dose reduction and withdrawal using each body weight cutoff value were calculated to draw receiver operating characteristic (ROC) curves (Fig. 4a). The optimal body weight cutoff value (the point at which the distance between the top-left corner of the graph and the ROC is smallest) that most effectively distinguished the high-risk group for early withdrawal or dose reduction of lenvatinib was $57.8 \mathrm{~kg}$, with a sensitivity of 0.77 and a specificity of 0.67 (false-positive rate, 0.33 ). Similarly, the best AUC cutoff value was 2,430 $\mathrm{ng} \times \mathrm{h} / \mathrm{mL}$ with a sensitivity of 0.71 and a specificity of 0.71 (false-positive rate, 0.29 ) (Fig. $4 \mathrm{~b}$ ).

\section{Significance of Maintaining the AUC within a Certain Range and Dose Adjustment in HCC}

Treatment with Lenvatinib

The AUC was better for predicting early withdrawal or dose reduction of lenvatinib than other factors such as sex, body weight, age, liver function, platelet count, Eastern Cooperative Oncology Group performance status, Child-Pugh class, hepatitis viral status, portal vein tumor thrombus, prior chemotherapy, prior antihypertensive therapy, and prior surgery. An AUC probability curve (Fig. 5) can predict early withdrawal or dose reduction of lenvatinib. Consequently, the AUC needs to be maintained below a certain level to reduce the occurrence of early withdrawal or dose reduction; for example, lenvatinib dose adjustment to maintain the AUC value below the optimal cutoff $(2,430 \mathrm{ng} \times \mathrm{h} / \mathrm{mL})$ may be recommended.

Based on the findings that the optimal body weight cutoff for a similar prediction was $57.8 \mathrm{~kg}$, the predicted AUC values for weight-based dosing (daily dose of 12 or $8 \mathrm{mg}$ in patients with a body weight $\geq 60$ or $<60 \mathrm{~kg}$, respectively) were calculated and plotted against body weight (Fig. 6). The predicted AUC values were in the range of 1,540-2,050 ng $\times \mathrm{h} / \mathrm{mL}$ in patients with a body weight $<60 \mathrm{~kg}$, and 1,410-2,310 $\mathrm{ng} \times \mathrm{h} / \mathrm{mL}$ in those with a body weight 


\section{Liver Cancer}

Fig. 5. Plot of the model-predicted probability of the occurrence of TEAEs leading to dose reduction or discontinuation during cycle 1 versus lenvatinib AUC. Filled squares represent the observed probability of responders for each AUC group, plotted at the median AUC of each group. Q1 group 25th percentile; Q2 group $>25$ th percentile and 50th percentile; Q3 group >50th percentile and 75th percentile; Q4 group $>75$ th percentile. AUC, area under plasma concentration-time curve at steady state; TEAE, treatmentemergent adverse event. Cited from Tamai et al. [15].

Fig. 6. Simulated body weight versus lenvatinib AUC for the 12and 8-mg dose groups. AUC indicates area under the plasma concentration-time curve at steady state, indicating that this weightbased dosing is adequate. Cited from Tamai et al. [15].

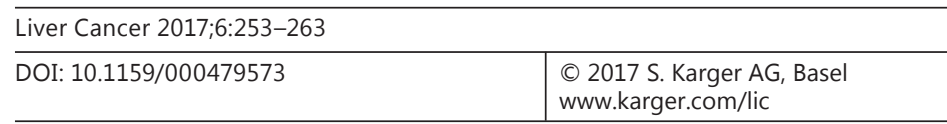

Kudo: Lenvatinib in Advanced Hepatocellular Carcinoma
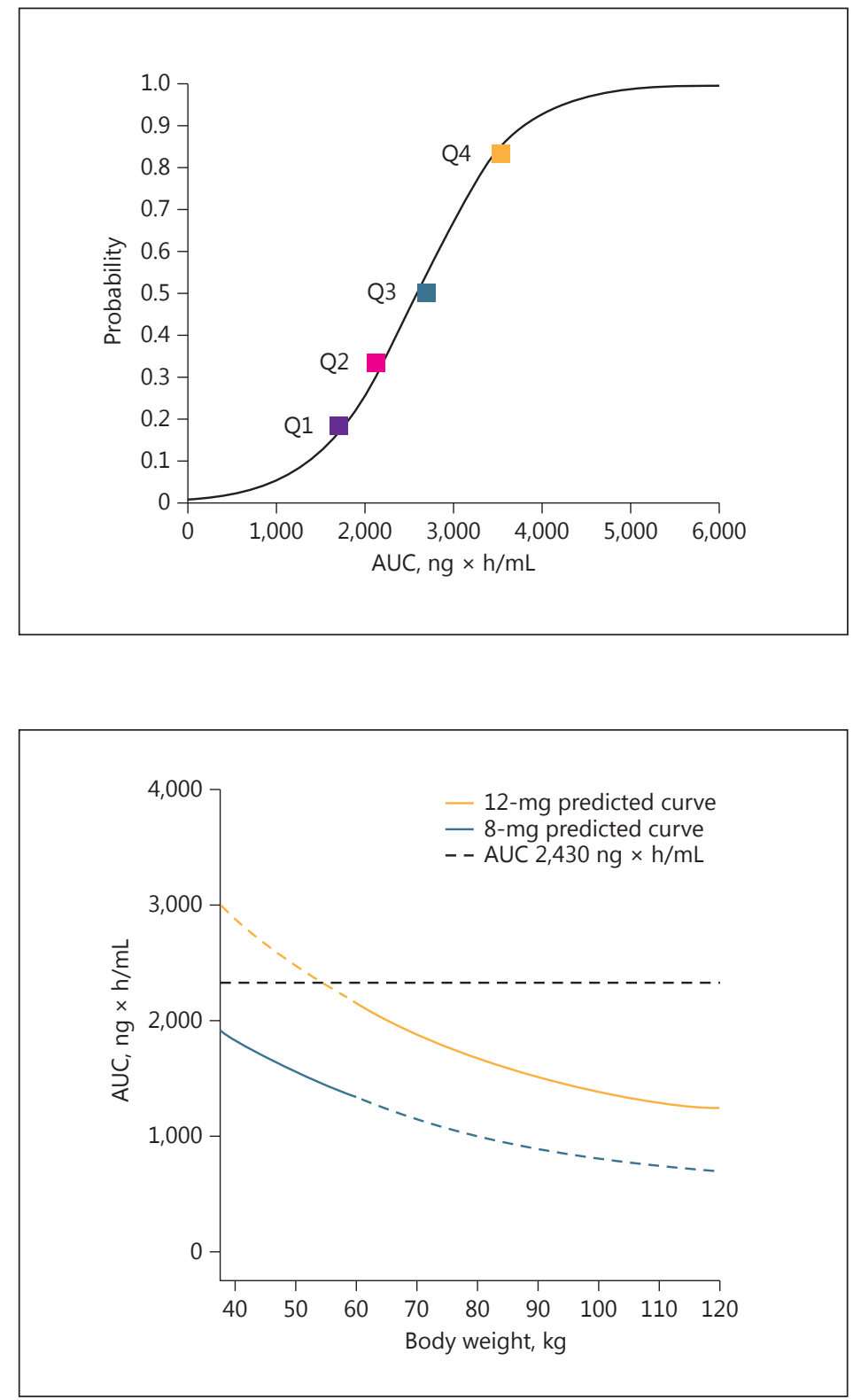

$\geq 60 \mathrm{~kg}$. These AUC ranges were quite similar and lower than 2,430 $\mathrm{ng} \times \mathrm{h} / \mathrm{mL}$ in both body weight categories, indicating that this weight-based dose adjustment may efficiently reduce early withdrawal and dose reduction of lenvatinib.

\section{Relationship between the AUC and Efficacy in HCC Treatment with Lenvatinib}

Because the lenvatinib dose adjustment to reduce the AUC could impair efficacy, patients enrolled in the phase II trial testing an initial daily dose of $12 \mathrm{mg}$ were grouped into a low AUC group (<2,050 $\mathrm{ng} \times \mathrm{h} / \mathrm{mL})$, an intermediate AUC group (>2,050 $\mathrm{ng} \times \mathrm{h} / \mathrm{mL}, \leq 2,750 \mathrm{ng} \times$ $\mathrm{h} / \mathrm{mL})$, and a high AUC group ( $>2,750 \mathrm{ng} \times \mathrm{h} / \mathrm{mL})$ to examine a relationship between AUC and efficacy. There was no trend in time-to-progression (TTP) among the three groups (Fig. 7), suggesting that a certain level of efficacy can be maintained even when the AUC is small. 
Fig. 7. Kaplan-Meier estimates of TTP, stratified by tertiles of lenvatinib AUC. TTP is similar among the 3 groups. AUC, area under the plasma concentration-time curve at steady state; TTP, time to progression. Cited from Tamai et al. [15]
Kudo: Lenvatinib in Advanced Hepatocellular Carcinoma

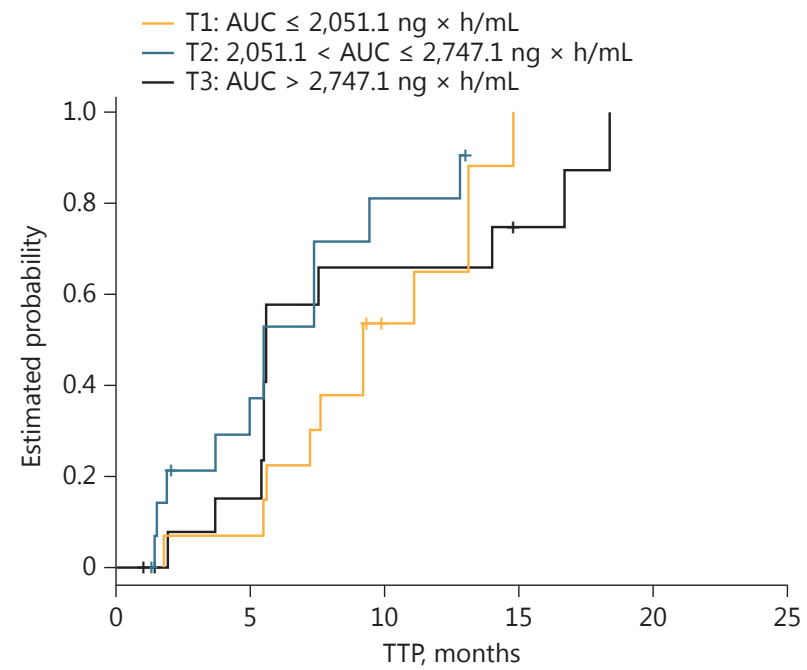

REFLECT trial: study schema

Global, randomized, open-label, phase III noninferiority study

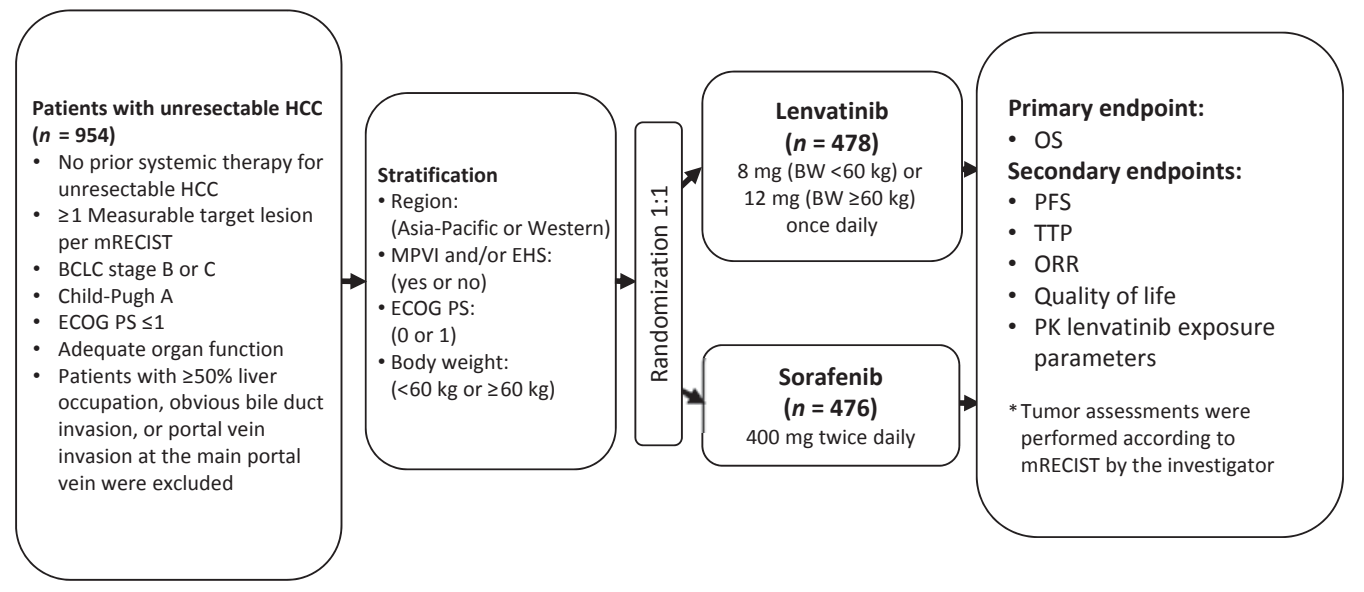

Fig. 8. Study diagram of the REFLECT trial. This is a global, randomized, open-label, phase III noninferiority study.

\section{Results of the Phase III REFLECT Trial}

The results of the REFLECT trial, a phase III study of lenvatinib, were presented at the ASCO annual meeting on June 4, 2017.

Patients with unresectable HCC who had not received systemic chemotherapy were randomized in a 1:1 ratio. Treatment was continued until disease progression or onset of an unacceptable adverse event. The primary endpoint was noninferiority in OS with a predefined noninferiority margin of 1.08. Secondary endpoints were progression-free survival (PFS), TTP, objective response rate (ORR), and safety (Fig. 8). 
Table 2. Results of the REFLECT trial

\begin{tabular}{llll}
\hline & $\begin{array}{l}\text { Lenvatinib } \\
(95 \% \mathrm{CI})(n=478)\end{array}$ & $\begin{array}{l}\text { Sorafenib } \\
(95 \% \mathrm{CI})(n=476)\end{array}$ & $\begin{array}{l}\text { Hazard ratio } \\
(95 \% \mathrm{CI})\end{array}$ \\
\hline Median OS, months & $13.6(12.1-14.9)$ & $12.3(10.4-13.9)$ & $0.92(0.79-1.06)$ \\
Median PFS, months* & $7.4(6.9-8.8)$ & $3.7(3.6-4.6)$ & $0.66(0.57-0.77)$ \\
Median TTP, months* & $8.9(7.4-9.2)$ & $3.7(3.6-5.4)$ & $0.63(0.53-0.73)$ \\
ORR, $n(\%)^{*}$ & $115(24)$ & $44(9)$ & - \\
\hline
\end{tabular}

OS, overall survival; PFS, progression-free survival; TTP, time to progression; ORR, overall response rate. $* p<0.0001$.

Table 3. Possible reasons for the success of REFLECT trial
- Good trial design

Weight-based dosing (12 vs. $8 \mathrm{mg}$ )

Noninferiority trial design

- Potent anticancer activity over sorafenib

- Acceptable toxicity

- Longer treatment duration due to better tolerability, especially less hand-foot-skin reaction (5.7 vs. 3.7 months)

- AFP imbalance favoring sorafenib arm

- Hepatitis C-related HCC imbalance favoring for sorafenib arm

- By excluding patients with main portal vein tumor thrombus and tumor burden $\geq 50 \%$, patients were relatively good prognostic population in both arms, leading to long postprogression survival (PPS) who likely received post trial treatments

- $\quad$ OS benefit was diluted by long PPS

Among 954 patients enrolled, 478 and 476 were assigned to the lenvatinib group and the sorafenib group, respectively. Noninferiority in the primary OS endpoint was statistically confirmed (13.6 vs. 12.3 months; hazard ratio, 0.92 [95\% CI, 0.79-1.06]). Increases in PFS, TTP, and ORR in the lenvatinib group were statistically significant (Table 2). Common adverse events of lenvatinib were hypertension, diarrhea, decreased appetite, weight loss, and fatigue, which was in good agreement with a previous study [4].

Because this study did not consider the $\alpha$-fetoprotein (AFP) level as a stratification factor, the lenvatinib group included more patients with a high AFP level $(\geq 200 \mathrm{ng} / \mathrm{mL})$ than the sorafenib group. After adjustment of the AFP imbalance, lenvatinib proved nominally superior to sorafenib in OS based on the post hoc analysis.

Taken together, the findings of the REFLECT trial showed that lenvatinib was statistically noninferior to sorafenib in OS and yielded statistically and clinically significant improvements in PFS, TTP, and ORR, indicating that lenvatinib is a highly promising first-line therapy for patients with unresectable HCC.

\section{Insights into the Success of the REFLECT Trial}

Several key factors might have contributed to this clinically meaningful success, the first in the past 10 years, in confirming the noninferiority of an alternative therapy to sorafenib. The REFLECT trial was the first anti-HCC trial that used a noninferiority trial design with body 
Table 5. Stratification factors in first-line phase III clinical trials in hepatocellular carcinoma

\begin{tabular}{|c|c|c|c|c|c|c|}
\hline $\begin{array}{l}\text { Study arm vs. } \\
\text { placebo arm }\end{array}$ & $\begin{array}{l}\text { SUN1170 } \\
\text { (sunitinib) }\end{array}$ & $\begin{array}{l}\text { BRISK-FL } \\
\text { (brivanib) }\end{array}$ & $\begin{array}{l}\text { LiGHT } \\
\text { (linifanib) }\end{array}$ & $\begin{array}{l}\text { SEARCH } \\
\text { (+erlotinib) }\end{array}$ & $\begin{array}{l}\text { CheckMate-459 } \\
\text { (nivolumab) }\end{array}$ & $\begin{array}{l}\text { REFLECT } \\
\text { (lenivatinib) }\end{array}$ \\
\hline $\begin{array}{l}\text { Stratification } \\
\text { factor }\end{array}$ & $\begin{array}{l}\text { Region } \\
\text { Vascular invasion } \\
\text { and/or extrahepatic } \\
\text { spread } \\
\text { Prior TACE }\end{array}$ & $\begin{array}{l}\text { ECOG-PS score } \\
\text { Extrahepatic spread } \\
\text { and/or vascular } \\
\text { invasion } \\
\text { Study site }\end{array}$ & $\begin{array}{l}\text { Region } \\
\text { ECOG-PS score } \\
\text { Vascular invasion } \\
\text { and/or extrahepatic } \\
\text { spread } \\
\text { Hepatitis B virus } \\
\text { infection }\end{array}$ & $\begin{array}{l}\text { Region } \\
\text { ECOG-PS score } \\
\text { Vascular invasion } \\
\text { and/or extrahepatic } \\
\text { spread } \\
\text { Smoking status }\end{array}$ & $\begin{array}{l}\text { Etiology } \\
\text { Region } \\
\text { Vascular invasion } \\
\text { and/or extrahepatic } \\
\text { spread }\end{array}$ & $\begin{array}{l}\text { Region } \\
\text { ECOG-PS score } \\
\text { Vascular invasion } \\
\text { and/or extrahepatic } \\
\text { spread } \\
\text { Body weight }\end{array}$ \\
\hline
\end{tabular}

Table 6. Recommendations for the design of phase II and phase III trials for patients with HCC (cited and modified from [24])

\begin{tabular}{|c|c|c|}
\hline Aim & Factor & Considerations and recommendations \\
\hline \multirow{3}{*}{$\begin{array}{l}\text { To select the target } \\
\text { population }\end{array}$} & BCLC stage & Include patients according to the specific BCLC stage $(\mathrm{A}-\mathrm{C})$ \\
\hline & Child-Pugh classification & $\begin{array}{l}\text { Include patients in Child-Pugh A to minimize deaths unrelated to } \\
\text { HCC }\end{array}$ \\
\hline & Biomarker-based enrichment & $\begin{array}{l}\text { Include subpopulations with specific activations of the signaling } \\
\text { pathway or oncogenic drivers }\end{array}$ \\
\hline \multirow{5}{*}{$\begin{array}{l}\text { To choose the } \\
\text { appropriate primary } \\
\text { endpoints }\end{array}$} & Overall survival & In phase III studies assessing primary treatments \\
\hline & Time to recurrence & In phase II/III studies assessing adjuvant treatments \\
\hline & $\begin{array}{l}\text { Time to progression or overall } \\
\text { response rate }\end{array}$ & In phase II studies assessing primary treatments \\
\hline & Surrogate endpoints & $\begin{array}{l}\text { Time to recurrence, time to progression and overall response have } \\
\text { to be assessed according to the modified RECIST criteria }\end{array}$ \\
\hline & Composite endpoints & Progression-free survival is a vulnerable endpoint in HCC \\
\hline \multirow{4}{*}{$\begin{array}{l}\text { To decide the } \\
\text { adequate control } \\
\text { treatment group }\end{array}$} & $\begin{array}{l}\text { Adjuvant therapy after resection or } \\
\text { local ablation }\end{array}$ & Placebo for control treatment group \\
\hline & Intermediate-stage disease test group & $\begin{array}{l}\text { Transcatheter arterial chemoembolization for the control } \\
\text { treatment goroup }\end{array}$ \\
\hline & $\begin{array}{l}\text { First-line treatment for } \\
\text { advanced-stage disease test group }\end{array}$ & Sorafenib plus supportive care for the control treatment group \\
\hline & $\begin{array}{l}\text { Second-line treatment for } \\
\text { advanced-stage disease test group }\end{array}$ & Placebo plus supportive care for the control treatment group \\
\hline \multirow{4}{*}{$\begin{array}{l}\text { To stratify factors } \\
\text { before randomization }\end{array}$} & Adjuvant & High risk (size $>3 \mathrm{~cm}, \mathrm{MVI}$ and satellites) and geographical region \\
\hline & Intermediate stage & Child-Pugh class, AFP and geographical region \\
\hline & First-line advanced stage & ECOG scale, MVI, EHS and geographical region \\
\hline & Second-line advanced stage & $\begin{array}{l}\text { ECOG scale, MVI, EHS, geographical region, AFP of }>400 \mathrm{ng} / \mathrm{mL} \text { and } \\
\text { type of progression }\end{array}$ \\
\hline
\end{tabular}

AFP, $\alpha$-fetoprotein; BCLC, Barcelona Clinic Liver Cancer; ECOG, Eastern Cooperative Oncology Group; EHS, extrahepatic spread; HCC, hepatocellular carcinoma; MVI, macrovascular invasion; RECIST, response evaluation criteria in solid tumors.

weight-based daily doses (12 or $8 \mathrm{mg}$ ). The GIDEON study used different doses of sorafenib according to the patients, with an initial dose of $800 \mathrm{mg}$ in $45.5 \%$ of the Japanese subpopulation; however, there was no clear evidence of the efficacy of lower sorafenib dosing [16]. In the REFLECT trial, efficacy was maintained and toxicity remained within acceptable limits in all body weight categories. In particular, there were few cases of hand-foot syndrome and patients were able to sustain therapy for longer periods ( 5.7 months in the lenvatinib arm vs. 3.7 months in the sorafenib arm) (Table 3 ). The antitumor activity was high, with a favorable ORR of $24 \%$.

The AFP level and macrovascular invasion were not used as independent stratification factors, resulting in an imbalance unfavorable to the lenvatinib group, with a higher number of sorafenib-responsive hepatitis C patients [17] in the sorafenib group. This may be one of 
the reasons why the superiority of lenvatinib in OS was not verified. In addition, the exclusion of patients with a tumor thrombus invading the main portal trunk (Vp4) and those with tumors occupying more than $50 \%$ of the liver might have resulted in the selective recruitment of patients who were highly likely to receive post-trial treatment and consequently to have a good prognosis [18-22] in both treatment arms. If so, post-trial treatment may have contributed to prolonging post-progression survival in both the lenvatinib and sorafenib arms, making that the OS benefit of lenvatinib may have been diluted since the hazard ratio of OS becomes high when post-progression survival is long $[23,24]$ (Table 4). Stratification by AFP level was not common when the REFLECT trial was started, and indeed, none of the relevant past and ongoing clinical studies of first-line therapies include AFP among stratification factors (Table 5). Furthermore, according to a report by Llovet et al. [25], the AFP level is not a recommended factor for stratification in first-line trials (Table 6). Analysis of covariance, which was performed to address the AFP imbalance, showed significant improvement in OS with lenvatinib compared to sorafenib (nominal $p=0.0342$ ).

\section{Conclusions}

Lenvatinib is the first anti-HCC agent for which noninferiority to sorafenib was statistically confirmed since the approval of sorafenib for the treatment of HCC approximately 10 years ago. The application for an additional indication for HCC has already been submitted in June 2017 in Japan, before anywhere else in the world. Therefore, therapeutic options in addition to sorafenib will become available in the near future for the treatment of unresectable HCC. Therapeutic combinations involving a tyrosine kinase inhibitor, such as lenvatinib, with an immune checkpoint inhibitor have potential as future treatment strategies [26].

\section{References}

1 Llovet JM, Ricci S, Mazzaferro V, Hilgard P, Gane E, Blanc JF, de Oliveira AC, et al: Sorafenib in advanced hepatocellular carcinoma. N Engl J Med 2008;359:378-390.

2 Cheng AL, Kang YK, Chen Z, Tsao CJ, Qin S, Kim JS, Luo R, et al: Efficacy and safety of sorafenib in patients in the Asia-Pacific region with advanced hepatocellular carcinoma: a phase III randomised, double-blind, placebo-controlled trial. Lancet Oncol 2009;10:25-34.

3 Kudo M: Molecular targeted agents for hepatocellular carcinoma: current status and future perspectives. Liver Cancer 2017;6:101-112.

4 Cheng AL, Kang YK, Lin DY, Park JW, Kudo M, Qin S, Chung HC, et al: Sunitinib versus sorafenib in advanced hepatocellular cancer: results of a randomized phase III trial. J Clin Oncol 2013;31:4067-4075.

5 Johnson PJ, Qin S, Park JW, Poon RT, Raoul JL, Philip PA, Hsu CH, et al: Brivanib versus sorafenib as first-line therapy in patients with unresectable, advanced hepatocellular carcinoma: results from the randomized phase III BRISK-FL study. J Clin Oncol 2013;31:3517-3524.

6 Cainap C, Qin S, Huang WT, Chung IJ, Pan H, Cheng Y, Kudo M, et al: Linifanib versus sorafenib in patients with advanced hepatocellular carcinoma: results of a randomized phase III trial. J Clin Oncol 2015;33:172-179.

7 Zhu AX, Rosmorduc O, Evans TR, Ross PJ, Santoro A, Carrilho FJ, Bruix J, et al: SEARCH: a phase III, randomized, double-blind, placebo-controlled trial of sorafenib plus erlotinib in patients with advanced hepatocellular carcinoma. J Clin Oncol 2015;33:559-566.

8 Vilgrain V, Bouattour M, Sibert A, Lebtahi R, Ronot M, Pageaux G-P, Guiu B, Barraud H, Silvain C, Gérolami R, Oberti F, Raoul JL, Costentin C, Samuel D, Dinut A, Pereira H, Chatellier G, Castera L: SARAH trial (SorAfenib vs. Radioembolization in Advanced Hepatocellular Carcinoma). J Hepatol 2017;66:S63-S94.

9 Chow PK, et al: Phase III multi-centre open-label randomized controlled trial of selective internal radiation therapy (SIRT) versus sorafenib in locally advanced hepatocellular carcinoma: the SIRveNIB study. J Clin Oncol 2017;35(suppl;abstr 4002).

10 Cheng A, Finn R, Qin S, et al: Phase III trial of lenvatinib (LEN) vs sorafenib (SOR) in first-line treatment of patients (pts) with unresectable hepatocellular carcinoma (uHCC). J Clin Oncol 2017;35(suppl;abstr 4001).

11 Tohyama O, Matsui J, Kodama K, Hata-Sugi N, Kimura T, Okamoto K, Minoshima Y, et al: Antitumor activity of lenvatinib (e7080): an angiogenesis inhibitor that targets multiple receptor tyrosine kinases in preclinical human thyroid cancer models. J Thyroid Res 2014;2014:638747. 
12 Yamamoto Y, Matsui J, Matsushima T, Obaishi H, Miyazaki K, Nakamura K, Tohyama O, et al: Lenvatinib, an angiogenesis inhibitor targeting VEGFR/FGFR, shows broad antitumor activity in human tumor xenograft models associated with microvessel density and pericyte coverage. Vasc Cell 2014;6:18.

13 Ikeda M, Okusaka T, Mitsunaga S, Ueno H, Tamai T, Suzuki T, Hayato S, et al: Safety and pharmacokinetics of lenvatinib in patients with advanced hepatocellular carcinoma. Clin Cancer Res 2016;22:1385-1394.

14 Ikeda K, Kudo M, Kawazoe S, Osaki Y, Ikeda M, Okusaka T, Tamai T, et al: Phase 2 study of lenvatinib in patients with advanced hepatocellular carcinoma. J Gastroenterol 2017;52:512-519.

15 Tamai T, Hayato S, Hojo S, Suzuki T, Okusaka T, Ikeda K, Kumada H: Dose finding of lenvatinib in subjects with advanced hepatocellular carcinoma based on population pharmacokinetic and exposure-response analyses. J Clin Pharmacol 2017, Epub ahead of print.

16 Kudo M, Lencioni R, Marrero JA, Venook AP, Bronowicki JP, Chen XP, Dagher L, et al: Regional differences in sorafenib-treated patients with hepatocellular carcinoma: GIDEON observational study. Liver Int 2016;36: 1196-1205.

17 Jackson R, Psarelli EE, Berhane S, Khan H, Johnson P: Impact of viral status on survival in patients receiving sorafenib for advanced hepatocellular cancer: a meta-analysis of randomized phase III trials. J Clin Oncol 2017;35:622-628.

18 Nagahama H, Okada S, Okusaka T, Ishii H, Ikeda M, Nakasuka H, Yoshimori M: Predictive factors for tumor response to systemic chemotherapy in patients with hepatocellular carcinoma. Jpn J Clin Oncol 1997;27:321324.

19 Chung GE, Lee JH, Kim HY, Hwang SY, Kim JS, Chung JW, Yoon JH, et al: Transarterial chemoembolization can be safely performed in patients with hepatocellular carcinoma invading the main portal vein and may improve the overall survival. Radiology 2011;258:627-634.

20 Kudo M: Molecular targeted therapy for hepatocellular carcinoma: where are we now? Liver Cancer 2015; 4:I-vii.

21 Kudo M: Why does every hepatocellular carcinoma clinical trial using molecular targeted agents fail? Liver Cancer 2012;1:59-60.

22 Llovet JM, Hernandez-Gea V: Hepatocellular carcinoma: reasons for phase III failure and novel perspectives on trial design. Clin Cancer Res 2014;20:2072-2079.

23 Broglio KR, Berry DA: Detecting an overall survival benefit that is derived from progression-free survival. J Natl Cancer Inst 2009;101:1642-1649.

24 Terashima T, Yamashita T, Takata N, Nakagawa H, Toyama T, Arai K, Kitamura K, et al: Post-progression survival and progression-free survival in patients with advanced hepatocellular carcinoma treated by sorafenib. Hepatol Res 2016;46:650-656.

25 Llovet JM, Zucman-Rossi J, Pikarsky E, Sangro B, Schwartz M, Sherman M, Gores G: Hepatocellular carcinoma. Nat Rev Dis Primers 2016;2:16018.

26 El-Khoueiry AB, Sangro B, Yau T, Crocenzi TS, Kudo M, Hsu C, Kim TY, et al: Nivolumab in patients with advanced hepatocellular carcinoma (CheckMate 040): an open-label, non-comparative, phase 1/2 dose escalation and expansion trial. Lancet 2017;389:2492-2502. 